ఠ

\title{
Applicability of the Rivermead Behavioural Memory Test - Third Edition (RBMT-3) in Korsakoff's syndrome and chronic alcoholics
}

This article was published in the following Dove Press journal:

Neuropsychiatric Disease and Treatment

20 June 2013

Number of times this article has been viewed

\author{
Arie JWester ${ }^{\prime}$ \\ Judith $C$ van Herten ${ }^{2}$ \\ Jos IM Egger ${ }^{2-4}$ \\ Roy PC Kessels $1,2,5$
}

'Korsakoff Clinic, Vincent van Gogh Institute for Psychiatry, Venray, The Netherlands; ${ }^{2}$ Donders Institute for Brain, Cognition and Behavior, Radboud University Nijmegen,

Nijmegen, The Netherlands; ${ }^{3}$ Centre of Excellence for Neuropsychiatry,

Vincent van Gogh Institute for

Psychiatry, Venray, The Netherlands;

${ }^{4}$ Behavioral Science Institute, Radboud

University Nijmegen, Nijmegen, The

Netherlands; ${ }^{5}$ Department of Medical

Psychology, Radboud University

Nijmegen Medical Centre, Nijmegen,

The Netherlands
Correspondence: Roy PC Kessels Korsakoff Clinic, Vincent van Gogh Institute of Psychiatry, D'n Herk 90, 5803 DN Venray, The Netherlands $\mathrm{Tel}+3$ I 24 36I254 I

Email r.kessels@donders.ru.nl
Purpose: To examine the applicability of the newly developed Rivermead Behavioural Memory Test - Third Edition (RBMT-3) as an ecologically-valid memory test in patients with alcoholrelated cognitive disorders.

Patients and methods: An authorized Dutch translation of the RBMT-3 was developed, equivalent to the UK version, and administered to a total of 151 participants - 49 patients with amnesia due to alcoholic Korsakoff's syndrome, 49 patients with cognitive impairment and a history of chronic alcoholism, not fulfilling the Korsakoff criteria, and 53 healthy controls. Between-group comparisons were made at subtest level, and the test's diagnostic accuracy was determined.

Results: Korsakoff patients performed worse than controls on all RBMT-3 subtests (all $P$-values $<0.0005$ ). The alcoholism group performed worse than controls on most (all $P$-values $<0.02$ ), but not all RBMT-3 subtests. Largest effects were found between the Korsakoff patients and the controls after delayed testing. The RBMT-3 had good sensitivity and adequate specificity.

Conclusion: The RBMT-3 is a valid test battery to demonstrate everyday memory deficits in Korsakoff patients and non-Korsakoff patients with alcohol abuse disorder. Korsakoff patients showed an impaired performance on subtests relying on orientation, contextual memory and delayed testing. Our findings provide valuable information for treatment planning and adjustment in patients with alcohol-related cognitive impairments.

Keywords: ecological validity, neuropsychological assessment, Korsakoff's syndrome, alcoholinduced persisting amnestic disorder, episodic memory, treatment outcome

\section{Introduction}

Chronic alcohol abuse may result in brain damage and cognitive deficits, such as impairment in memory function, but also deficits in executive functions. For example, in Korsakoff's syndrome, chronic thiamine deficiency may result in bilateral lesions of the diencephalon, including the mammillary bodies and thalamus, which may produce severe anterograde and (to a lesser extent) retrograde amnesia. ${ }^{1}$ Specifically, the episodic aspect of long-term memory is impaired in Korsakoff patients, ${ }^{2}$ like memory for contextual information as such (eg, spatial information or temporal-order memory) and the ability to associate context and target information, that is, the "what, where and when' of everyday experiences. Milder forms of memory deficits have been reported in non-Korsakoff chronic alcoholics, due to the neurotoxic nature of alcohol that may result in global brain atrophy. ${ }^{3}$

A wide variety of neuropsychological tests is available to examine memory function in brain injured adults, such as the California Verbal Learning Test (CVLT), the Rey 
Auditory Verbal Learning Test (RAVLT) and the Wechsler Memory Scale - Fourth edition (WMS-IV). ${ }^{4}$ However, many of these tests have been criticized as they may lack the ability to predict daily-life functioning (often referred to as ecological validity). ${ }^{5}$ The Rivermead Behavioural Memory Test (RBMT) has been specifically developed as a measure of everyday memory function. ${ }^{6}$ Also, parallel versions of the test were developed, making this memory battery applicable for treatment outcome assessment. The RBMT has been widely used for examining patients with alcoholrelated cognitive disorders, and has been recommended for use in Korsakoff patients given its relevance for daily memory problems. ${ }^{7}$ Duffy and O'Carroll, ${ }^{8}$ for instance, demonstrated that compared to other memory tests, the RBMT resulted in the largest effect sizes when comparing Korsakoff patients with other neuropsychiatric patients (ie, patients with schizophrenia). Several other studies also reported profound deficits in Korsakoff patients compared to normative data. ${ }^{9,10}$ Furthermore, the RBMT has been used to examine treatment effects of fluvoxamine in Korsakoff patients on memory function. ${ }^{11}$ The RBMT has also been applied in the study of non-Korsakoff alcohol users. For example, Van Balen et al ${ }^{12}$ have examined a heterogeneous group of alcohol-related cognitive disorders, showing poor performances on the RBMT. Others have administered the RBMT in long-abstinent alcoholics without $\mathrm{KS}$, showing an unimpaired memory performance which may be due to recovery. ${ }^{13}$

However, while successful and widely used, the original RBMT suffered from a lack of sensitivity on some subtests, ${ }^{14}$ as many subtests consisted of only a small number of items. The third edition of this test (RBMT-3) has overcome this problem by updating a number of stimuli, extending the number of trials in several subtests and by adding a new subtest. ${ }^{15}$ The RBMT-3 consists of a number of subtests, each of which addresses an important aspect of everyday memory function. For instance, patients have to remember a route, a short story or a message, must recall photographs of people, and have to remember to retrieve a personal belonging at the end of the examination. Also, orientation is tested and a newly developed puzzle subtest is included, in which participants have to relay puzzle pieces in a specific order. Thus, the RBMT-3 assesses verbal and nonverbal episodic memory, spatial memory, and aspects of prospective memory, and procedural memory. In several subtests, memory is tested both immediately after stimulus presentation and after a filled delay. The RBMT-3 has been examined in relatively small samples of patients with traumatic brain injury, stroke, encephalitis and neurodegenerative diseases (eg, Alzheimer's disease). ${ }^{15}$ To date, however, no studies have been published using the RBMT-3 in patients with alcoholrelated cognitive deficits, while the original RBMT - despite its limitations - is still being used clinically. The present study examines the memory profile of amnesic patients with alcoholic Korsakoff's syndrome using the RBMT-3 as a supposedly ecologically valid memory test battery, comparing their performance to non-Korsakoff chronic alcoholics (with mild cognitive impairments) and healthy controls.

\section{Material and methods Study design and participants}

We have performed a case-control study using a convenience sample of patients with alcohol-abuse disorder that were diagnosed with Korsakoff's syndrome or had less severe memory deficits, as well as matched healthy controls. Recruited patients were inpatients of the Korsakoff clinic of Vincent van Gogh Institute for Psychiatry in Venray, the Netherlands. The Korsakoff patients fulfilled the DSMIV-TR criteria for alcohol-induced persisting amnestic disorder (DSM-IV-TR code 291.1), that is, a memory deficit had to be present that results in severe deficits in social functioning, in the absence of delirium or dementia, with a history of alcohol-abuse disorder. In addition, the criteria for alcoholic Korsakoff's syndrome ${ }^{1}$ had to be met: evidence for a history of Wernicke encephalopathy, confabulation behavior and evidence for malnutrition or thiamine deficit. The patients with cognitive impairment and a history of chronic alcoholism (DSM-IV-TR Alcohol Dependence, DSM-IV-TR code 303.90) and fulfilled the DSM-IV-TR criteria for cognitive disorder not otherwise specified (DSMIV-TR code 294.9). All diagnoses were supported by medical history, psychiatric assessment, neuropsychological testing covering all major cognitive domains and neuroradiological findings, and all patients had been abstinent from alcohol for at least six weeks. None of the patients had any evidence for brain abnormalities that could account for their condition apart from atrophy or white-matter lesions associated with the chronic alcohol abuse. None of the participants fulfilled the proposed criteria for alcohol-related dementia, ${ }^{16}$ and none of the participants had any hearing problems, language or communication deficits, or visual agnosia that could confound the performance on memory tests.

Healthy participants were recruited from the clinic's staff, databases of healthy volunteers, and the network of the researchers. Exclusion criteria for controls were a psychiatric or neurologic history or subjective memory 
complaints (self-report). Education level was assessed using 7 categories in accordance with the Dutch educational system ( 1 = less than primary school; $7=$ university degree). The Dutch version of the National Adult reading Task (NART) was administered to estimate verbal intelligence level (IQ). ${ }^{17}$

\section{Materials}

An authorized Dutch translation of the RBMT-3 was constructed to be equivalent to the previously published UK version of this test. ${ }^{15}$ Test items and test instructions were translated into Dutch and back translated into British English by native speakers. Differences in phrasing or meaning were resolved by discussion, resulting in a Dutch-language research version of the RBMT-3 that was used in the current study. The RBMT-3 consists of ten subtests (maximum score between brackets): Names (remembering the first and second names of two portrait photos; $\max =8$ ), Belongings (remembering to ask for two personal belongings at the end of the test session; $\max =8$ ), Appointments (asking two questions when an alarm rings 25 minutes later; $\max =4$ ), Picture Recognition (delayed recognition of line drawings; $\max =15$ ), Story (immediate and delayed recall of a short news story; $\max =2 \times 21$ ), Faces (delayed recognition of photographs of faces; $\max =15$ ), Route (immediate and delayed recall of a short route in the examination room; $\max =2 \times 13$ ), Message (immediate and delayed remembering to pick up an envelope and book; $\max =2 \times 6$ ), Orientation and Date (orientation to person, place and time; max $=14$ ), and Novel Task (immediate and delayed recall of puzzle pieces laid in a specific order within a template; max for three immediate trials $=51$; max for delayed recall $=17$ ) . Administration of the RBMT-3 was performed in accordance with the test's manual by trained neuropsychologists or research assistants and took approximately 30 minutes. In addition to the raw scores on the subtests, the Global Memory Index (GMI) was computed as an overall memory performance measure.

\section{Analysis}

Multivariate analyses of variance (General Linear Model) were performed using the performance on the individual subtests of the RBMT-3 for the three groups. Bonferronicorrected post-hoc analyses were performed to compare the specific groups (KS-CON, ALC-CON and KS-ALC), all post-hoc $P$-values reported are SPSS-adjusted $P$-values, and effect sizes (Cohen's d) were computed. Additionally, receiver operating characteristic (ROC) analyses were performed on the GMI to determine the test's diagnostic accuracy, comparing the KS and the ALC group and the ALC and CON groups. Cut-off scores for the GMI were determined that had good sensitivity $(\geq 0.8)$ and adequate specificity $(\geq 0.6) .{ }^{18}$ All analyses were performed using IBM SPSS Statistics Version 19. Alpha was set at 0.05 for all analyses.

\section{Results}

A total of 151 participants enrolled in this study, consisting of 49 patients with Korsakoff's syndrome (KS), 49 patients with cognitive impairment and a history of chronic alcoholism (ALC), and 53 healthy controls (CON). Table 1 shows the demographic variables for the three groups of participants. The groups did not differ with respect to age $(F[2,148]=0.2)$, but differed with respect to education level $\left(\chi^{2}[2]=9.6, P=0.008\right)$ and IQ $(F[2,138]=3.4, P=0.04)$. The healthy controls had on average a higher education level than the KS patients (Mann-Whitney $U=979.5$, $Z=2.6, P=0.011)$ and the ALC group $(U=1032.5, Z=2.2$, $P=0.035$ ), although in all three groups most participants had an average education level (categories 4 and 5). Bonferronicorrected post-hoc tests comparing the KS, ALC and CON groups directly did not reveal significant IQ differences (all $P$-values $>0.05)$. The groups differed with respect to sex distribution $\left(\chi^{2}[2]=7.9, P=0.02\right)$, with fewer women $\mathrm{KS}$ and ALC patients compared to the healthy control group $(U=907.5, Z=2.3,0=0.021 ; U=820.5, Z=2.9, P=0.003$ respectively).

Table 2 shows the results of the individual RBMT-3 subtests for the three groups. GLM analysis taking all subtests together demonstrated an overall main effect of Group $(F[28,272]=7.4, P<0.0005)$. Subsequent multivariate GLM analyses on the individual subtests demonstrated an overall Group effect on all individual subtests (all $F$-values $>10.7$, all $P$-values $<0.001)$. Post-hoc analyses comparing the patient groups with the controls, demonstrated a significant worse performance than controls on all subtests for the KS group (all $P$-values $<0.0005$ ). The ALC group performed

Table I Demographic variables for the Korsakoff patients (KS), the cognitively impaired alcoholics (ALC) and the healthy controls (CON)

\begin{tabular}{|c|c|c|c|}
\hline & KS & ALC & CON \\
\hline $\begin{array}{l}\text { Age (years; mean } \pm \text { standard } \\
\text { deviation) }\end{array}$ & $55.6(6.4)$ & $55.0(6.7)$ & $54.9(7.2)$ \\
\hline Education level (mode + [range]) & $4(2-6)$ & $4(I-7)$ & $5(3-7)$ \\
\hline $\begin{array}{l}\text { NART-IQ (mean } \pm \text { standard } \\
\text { deviation) }\end{array}$ & $90.3(14.0)$ & $90.9(16.8)$ & $97.2(10.4)$ \\
\hline Sex (male: female) & $37: 12$ & $35: 14$ & $27: 26$ \\
\hline
\end{tabular}

Abbreviation: NART, National Adult Reading Test. 
Table 2 Performance (mean number of correct items) on the RBMT-3 subtests for the Korsakoff patients (KS), the cognitively impaired alcoholics (ALC) and the healthy controls (CON)

\begin{tabular}{|c|c|c|c|c|c|c|c|c|}
\hline \multirow[t]{2}{*}{ RBMT-3 subtest } & \multicolumn{3}{|c|}{$\begin{array}{l}\text { KS } \\
(n=49)\end{array}$} & \multicolumn{3}{|c|}{$\begin{array}{l}\text { ALC } \\
(n=49)\end{array}$} & \multicolumn{2}{|c|}{$\begin{array}{l}\text { CON } \\
(n=53)\end{array}$} \\
\hline & Mean & SD & d & Mean & SD & d & Mean & SD \\
\hline Names & 2.27 & 2.32 & $-1.8 \mid$ & 3.98 & 2.59 & -0.89 & 5.66 & 1.88 \\
\hline Belongings & 4.24 & 1.92 & -2.21 & 5.90 & 2.10 & -0.82 & 6.87 & 1.19 \\
\hline Appointments & 0.94 & 1.05 & -2.46 & 2.31 & $\mathrm{I} .40$ & -0.99 & 3.23 & 0.93 \\
\hline Picture Recognition - delayed & 12.16 & 2.78 & -4.03 & 14.08 & 1.30 & -0.93 & 14.66 & 0.62 \\
\hline Story Recall - immediate & 3.74 & 2.42 & -0.92 & 4.91 & 2.79 & $-0.5 \mathrm{I}$ & 6.37 & 2.85 \\
\hline Story Recall - delayed & 1.56 & 2.25 & -1.39 & 4.02 & 2.92 & -0.45 & 5.19 & 2.61 \\
\hline Face Recognition - delayed & 8.86 & 3.27 & -3.57 & 11.27 & 2.48 & -1.64 & 13.32 & 1.25 \\
\hline Route Recall - immediate & 6.20 & 2.42 & -1.70 & 8.27 & 2.60 & -0.90 & 10.58 & 2.58 \\
\hline Route Recall - delayed & 4.78 & 2.58 & -2.38 & 7.80 & 2.87 & -1.20 & 10.89 & 2.57 \\
\hline Messages - immediate & 4.57 & 1.67 & -1.32 & 5.29 & 0.91 & -0.44 & 5.64 & 0.81 \\
\hline Messages - delayed & 2.94 & 1.91 & -2.55 & 4.69 & 1.40 & $-0.8 \mathrm{I}$ & 5.51 & 1.01 \\
\hline Orientation and date & 8.76 & 2.85 & -2.97 & 11.66 & 1.44 & -0.59 & 12.38 & 1.22 \\
\hline Novel Task - immediate & 18.92 & 10.45 & -1.95 & 27.92 & 10.79 & -0.93 & 36.19 & 8.86 \\
\hline Novel Task - delayed & 5.47 & 3.95 & -2.67 & $|1.3|$ & 4.81 & -0.81 & 13.85 & 3.14 \\
\hline GMI & 61.16 & 8.54 & -2.63 & 76.00 & 11.96 & -1.39 & 92.58 & 11.94 \\
\hline
\end{tabular}

Abbreviations: RBMT-3, Rivermead Behavioural Memory Test - Third Edition; GMI, Global Memory Index; d, Cohen's d, comparing patients with the controls; SD, standard deviation.

worse than controls on most subtests (all $P$-values $<0.02$ ), but not on the subtests Picture Recognition, Story Recall Delayed, Messages - Immediate, and Orientation, on which the performance did not differ significantly from controls. Directly comparing both patient groups showed a worse performance in the $\mathrm{KS}$ group compared to the ALC group on most subtests (all $P$-values $<0.001$ ), except on the subtest Story Recall - Immediate on which no statistically significant difference was found $(P=0.10)$. With respect to effect sizes, large effects were found on all subtests, with the largest differences between the KS and CON group after delayed testing on Picture Recognition, Face Recognition, Route Recall, Messages, and the Novel Task, as well as on the subtests Belongings, Appointments and Orientation. Adjusting the analyses by including education level as a covariate did not alter the results (data not shown).

ROC analyses revealed that the RBMT-3 GMI had a statistically significant diagnostic accuracy in distinguishing $\mathrm{KS}$ patients from ALC patients $(\mathrm{AUC}=0.85 ; 95 \% \mathrm{CI}$ $0.78-0.93 ; P<0.0005)$. A cut-off score of GMI $<67.5$ had a sensitivity of 0.80 and a specificity of 0.69 . The GMI could also distinguish ALC patients from healthy controls (AUC $=0.83 ; 95 \%$ CI 0.75-0.91; $P<0.0005)$. A GMI cut-off of 87.5 had a sensitivity of 0.80 and a specificity of 0.62 .

\section{Discussion}

Aim of the present study was to examine whether the RBMT-3 can be used to demonstrate alcohol-related memory deficits, and whether it is able to distinguish patients with KS from patients with more subtle alcohol-related memory deficits, and the latter from healthy controls. Our findings clearly show that both patients with $\mathrm{KS}$ and non-Korsakoff-alcoholics with cognitive deficits perform worse than matched controls on the RBMT-3. Looking at the pattern of impairments, largest effect sizes were found on tests of delayed recall, orientation, as well as cued and uncued prospective memory in the KS patients. This is in agreement with the presumed neural substrate of Korsakoff's syndrome, that is, diencephalic lesions in the mammillary bodies and the thalamus. ${ }^{19}$ Also, some studies have reported hippocampal atrophy in KS patients. ${ }^{20,21}$ As a result, long-term storage of new information is hampered by a deficit in consolidation, ${ }^{22}$ which strongly relies on medialtemporal lobe and diencephalic structures. ${ }^{2}$ Looking at the type of task that is tested after a delay, recognition tasks such as Face Recognition or Picture Recognition do not improve the memory performance, which also points towards a consolidation deficit rather than impaired retrieval, as in the latter recognition performance is expected to improve substantially. ${ }^{23}$ The deficit in delayed memory ("rapid forgetting") has also been directly associated with lesions of KS patients in the diencephalon and hippocampus. ${ }^{21}$ Deficits on Route Recall and Messages in KS patients may be related to an impaired memory for contextual information, notably spatial memory and object-context integration. ${ }^{2}$ The impaired performance on the Novel Task may partly be due to a deficit in motor or procedural learning. While implicit learning in $\mathrm{KS}$ has been 
shown to be preserved (eg, on visuoperceptual tasks or simple motor learning), ${ }^{24,25}$ impaired performance on more complex procedural tasks, such as spatial pattern learning or a Tower paradigm, have been demonstrated in KS patients. ${ }^{24,26}$ Also, performance on the Novel Task may rely on non-procedural processes, such as spatial working memory (in the immediate test) and visuospatial episodic recall after delayed testing. Finally, prospective memory deficits in KS patients have been linked to prefrontal dysfunction, ${ }^{27}$ or may be explained by the general inability to encode and consolidate information over longer periods of time, although studies are lacking examining prospective memory in more detail in KS patients.

With respect to the non-Korsakoff alcoholics, effect sizes in the ALC group compared to the controls were smaller than in the KS group, and the performance did not differ from the healthy participants on all subtests. That is, orientation, memory for pictures, messages and prose recall were at control level. KS patients also performed worse than the ALC group on all but one RBMT-3 subtest. These results are in agreement with a previous study that also demonstrated unimpaired performance on the original RBMT subtest Story Recall in chronic alcoholics. ${ }^{28}$ In contrast, a study in long-abstinent chronic alcoholics reported an unimpaired performance on all original RBMT subtests. ${ }^{13}$ The discrepancy with our study in which we show memory deficits on many RBMT-3 subtests in non-Korsakoff chronic alcoholics could be due to recovery, as their patients have been abstinent over 6 months, while the chronic alcoholics in the present study sample had been abstinent for 6 weeks. Moreover, a recruitment bias may be present, as the nonKorsakoff chronic alcoholics in our clinic are being referred because of possible cognitive deficits. Alternatively, these apparently mixed results may also be the result of the relative insensitivity of the original RBMT. That is, previously ${ }^{29}$ we showed by directly comparing the performance on the RBMT and the RBMT-3 that the latter is more sensitive in detecting alcohol-related memory deficits and that ceiling effects are present on some subtests. The effect sizes of the ALC group in the present study were in the moderate to large range,$^{30}$ indicating that while the memory impairments on the RBMT-3 are not as profound as in KS, they are clinically relevant and may hamper everyday functioning.

The Global Memory Index of the RBMT-3 showed good diagnostic accuracy to distinguish KS patients from milder forms of memory deficits after alcohol-abuse disorder, and the latter group from healthy controls. However, these results should be interpreted with some caution, as there may be a risk of circularity here. That is, although the diagnoses were made based on medical history, radiological findings, and extensive cognitive testing, also in non-memory domains and using other memory tests such as the California Verbal Learning Test, having 'amnesia' is part of the diagnostic criteria for KS which has to be diagnosed using neuropsychological tests. Still, the presented cut-off values shown here may be useful for clinicians working with patients with alcohol-abuse disorder that are suspected of having memory deficits.

While the Rivermead Behavioral Memory tests batteries have been developed to assess everyday memory performance presumably adopting a more ecologically valid approach, the ecological validity of this test battery has also been criticized. For example, Koltai et $\mathrm{al}^{31}$ compared the performance of a group of patients that had been exposed to neurotoxic agents on the revised Wechsler Memory Scale (WMS-R, a 'nonecological' memory battery) and the RBMT, and could neither demonstrate significant differences between the two tests, nor establish any incremental value of administering a combination of the two memory batteries. Others ${ }^{32}$ showed that RBMT total score could not significantly predict functional status in patients with multiple sclerosis (MS). In that study, both delayed RBMT Story Recall and delayed recall of the CVLT predicted functional status at subtest level, questioning the added value of ecologically valid memory tests. However, in that study some RBMT subtests were not administered because of ceiling effects in MS patients, which may also explain this lack of statistical significance. With respect to the RBMT-3, only modest correlations have been found between the GMI and self- and proxy-rated versions of a rating scale for everyday memory problems..$^{15}$ However, no studies have yet been performed in people with alcohol-related cognitive disorders or in any other patient sample using the RBMT-3 that specifically examine the test's predictive validity for other ecological outcome measures, such as return to work or ability to live independently in people with alcohol-related cognitive disorders or any other patient sample. Finally, it should be noted that not all aspects of memory can be examined using the RBMT-3. That is, the test does not include subtests assessing working memory or semantic memory, which would be relevant as deficits in these memory functions have also

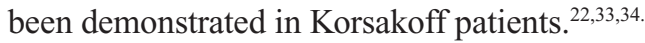

Our results showing memory deficits in patients with alcohol-abuse disorder also emphasize concurrent findings that treatment in patients with alcohol-abuse disorder should not only be limited to the addiction itself. That is, the cognitive deficits should be taken into account as well, ${ }^{35}$ for example by incorporating strategy or other compensatory trainings based on cognitive rehabilitation principles. 
Moreover, the presence of severe cognitive deficits also requires adjustment of the available treatment programs in addiction care. ${ }^{36}$ For example, group psychotherapy sessions may be less effective in cognitively-impaired patients, as a lot of information is being shared. Also, cognitive deficits affect the applicability of cognitive-behavioral therapy, which relies on self-reflection, sharing of conceptualizations, and explicitly remembering stressful situations. Finally, a detailed profile of everyday memory (dys)function provides specific information about an individual patient that can guide care professionals and optimize clinical management.

\section{Conclusion}

Our present results show that the RBMT-3 seems to have clinical relevance for the assessment of severe memory deficits in KS patients on the one hand and milder memory impairments associated with chronic alcohol abuse on the other. Especially the performance on subtests relying on orientation, contextual memory and delayed testing are impaired in KS patients, related to the presumed underlying dysfunction in hippocampal-diencephalic brain regions. The deficits in the ALC group are less severe, and on some subtests even at control level. Our findings stress that cognitive impairment should on the one hand also be considered in the treatment of patients with alcohol-use disorder (eg, using cognitive rehabilitation), and available addiction therapies should be adjusted for patients with limitations in cognitive processing capacities. Future studies should examine the ecological validity (ie, predictive value) of the RBMT-3 for everyday function in these patients. In addition, the validity of changes in performance on the RBMT-3 parallel version as an outcome measure of, for example, cognitive rehabilitation or spontaneous recovery in non-Korsakoff alcoholics, remains to be determined.

\section{Acknowledgment/disclosure}

The authors report no conflicts of interest in this work. We thank Pearson Assessment B.V., Amsterdam, for providing the RBMT-3 test materials and for authorizing the Dutch translation.

\section{References}

1. Kopelman MD. Disorders of memory. Brain. 2002;125:2152-2190.

2. Kessels RPC, Kopelman MD. Context memory in Korsakoff's syndrome. Neuropsychol Rev. 2012;22:117-131.

3. Green A, Garrick T, Sheedy D, Blake H, Shores EA, Harper C. The effect of moderate to heavy alcohol consumption on neuropsychological performance as measured by the repeatable battery for the assessment of neuropsychological status. Alcohol Clin Exp Res. 2010;34:443-450.
4. Lezak MD, Howieson DB, Bigler ED, Tranel D. Neuropsychological Assessment. New York: Oxford University Press; 2012.

5. Wilson BA. Ecological validity of neuropsychological assessment: do neuropsychological indexes predict performance in everyday activities? Appl Prev Psychol. 1993;2:209-215.

6. Wilson B, Cockburn J, Baddeley A, Hiorns R. The development and validation of a test battery for detecting and monitoring everyday memory problems. J Clin Exp Neuropsychol. 1989;11:855-870.

7. Smith I, Hillman A. Management of alcohol Korsakoff syndrome. $A d v$ Psychiatr Treat. 1999;5:271-278.

8. Duffy L, O'Carroll R. Memory impairment in schizophrenia: a comparison with that observed in the Alcoholic Korsakoff syndrome. Psychol Med. 1994;24:155-165.

9. Brunfaut E, d'Ydewalle G. A comparison of implicit memory tasks in Korsakoff and alcoholic patients. Neuropsychologia. 1996;34: $1143-1150$

10. Kopelman MD. Remote and autobiographical memory, temporal context memory and frontal atrophy in Korsakoff and Alzheimer patients. Neuropsychologia. 1989;27:437-460.

11. O'Carroll RE, Moffoot AP, Ebmeier KP, Goodwin GM. Effects of fluvoxamine treatment on cognitive functioning in the alcoholic Korsakoff syndrome. Psychopharmacology. 1994;116:85-88.

12. Van Balen HGG, Westzaan PSH, Mulder T. Stratified Norms for the Rivermead Behavioural Memory Test. Neuropsychol Rehabil. 1996;6: 203-218.

13. Mlinarics R, Kelemen O, Sefcsik T, Németh D. Cognitive impairment in patients with alcoholism after long-term abstinence. Neuropsychopharmacol Hung. 2009;11:135-139.

14. Wilson B, Cockburn J, Baddeley A. The Rivermead Behavioural Memory Test. Bury St Edmunds, UK: Thames Valley Test Company; 1985.

15. Wilson BA, Greenfield E, Clare L, et al. The Rivermead Behavioural Memory Test - Third Edition (RBMT-3). London, UK: Pearson Assessment; 2008.

16. Oslin D, Atkinson RM, Smith DM, Hendrie H. Alcohol related dementia: proposed clinical criteria. Int J Geriatr Psychiatry. 1998;13: 203-212.

17. Schmand B, Bakker D, Saan R, Louman J. The Dutch Reading Test for Adults: a measure of premorbid intelligence level. Tijdschr Gerontol Geriatr. 1991;22:15-19.

18. Kessels RPC, Mimpen G, Melis R, Olde Rikkert MGM. Measuring impairments in memory and executive function in older people using the Revised Cambridge Cognitive Examination (CAMCOG-R). Am J Geriatr Psychiatry. 2009;17:793-801.

19. PitelAL, Chételat G,Le Berre AP, Desgranges B, Eustache F, Beaunieux H. Macrostructural abnormalities in Korsakoff syndrome compared with uncomplicated alcoholism. Neurology. 2012;78:1330-1333.

20. Sullivan EV, Pfefferbaum A. Neuroimaging of the Wernicke-Korsakoff syndrome. Alcohol Alcohol. 2009;44:155-165.

21. Visser PJ, Krabbendam L, Verhey FR, et al. Brain correlates of memory dysfunction in alcoholic Korsakoff's syndrome. J Neurol Neurosurg Psychiatry. 1999;67:774-778.

22. Kopelman MD, Bright P, Fulker H, Hinton N, Morrison A, Verfaellie M. Remote semantic memory in patients with Korsakoff's syndrome and herpes encephalitis. Neuropsychology. 2009;23:144-157.

23. Duchnick JJ, Vanderploeg RD, Curtiss G. Identifying retrieval problems using the California Verbal Learning Test. J Clin Exp Neuropsychol. $2002 ; 24: 840-851$

24. Van Tilborg IA, Kessels RP, Kruijt P, Wester AJ, Hulstijn W. Spatial and nonspatial implicit motor learning in Korsakoff's amnesia: evidence for selective deficits. Exp Brain Res. 2011;214:427-435.

25. Fama R, Pfefferbaum A, Sullivan EV. Visuoperceptual learning in alcoholic Korsakoff syndrome. Alcohol Clin Exp Res. 2006;30: 680-687.

26. Beaunieux H, Pitel AL, Witkowski T, Vabret F, Viader F, Eustache F. Dynamics of the cognitive procedural learning in alcoholics with Korsakoff's syndrome. Alcohol Clin Exp Res. 2013;37:1025-1032. 
27. Oscar-Berman M. Function and dysfunction of prefrontal brain circuitry in alcoholic Korsakoff's syndrome. Neuropsychol Rev. 2012;22: 154-169.

28. Uekermann J, Daum I, Schlebusch P, Wiebel B, Trenckmann U. Depression and cognitive functioning in alcoholism. Addiction. 2003;98:1521-1529.

29. Wester AJ, Leenders P, Egger JIM, Kessels RPC. Ceiling and floor effects on the Rivermead Behavioural Memory Test in patients with alcoholrelated memory disorders and healthy participants. Int J Psychiatry Clin Pract. In press 2013.

30. Cohen J. Statistical Power Analysis for the Behavioral Sciences (second edition). Hillsdale, NJ: Lawrence Erlbaum Associates; 1988.

31. Koltai DC, Bowler RM, Shore MD. The Rivermead behavioural memory test and Wechsler memory scale-revised: Relationship to everyday memory impairment. Assessment. 1996;3:443-448.

32. Higginson CI, Arnett PA, Voss WD. The ecological validity of clinical tests of memory and attention in multiple sclerosis. Arch Clin Neuropsychol. 2000;15:185-204.
33. Bardenhagen FJ, Oscar-Berman M, Bowden SC. Rule knowledge aids performance on spatial and object alternation tasks by alcoholic patients with and without Korsakoff's amnesia. Neuropsychiatr Dis Treat. 2007;3:907-918.

34. Van Geldorp B, Bergmann HC, Robertson J, Wester AJ, Kessels RPC. The interaction of working memory performance and episodic memory formation in patients with Korsakoff's amnesia. Brain Res. 2012;1433:98-103.

35. Walvoort SJW, Wester AJ, Egger JIM. Assessment of psychopathology and personality with the MMPI-2 in patients with alcohol use disorder (AUD): should we not correct for associated cognitive dysfunctions? Clin Neuropsychiatry. 2012;9:212-220.

36. Bates ME, Bowden SC, Barry D. Neurocognitive impairment associated with alcohol use disorders: implications for treatment. Exp Clin Psychopharmacol. 2002;10:193-121.
Neuropsychiatric Disease and Treatment

\section{Publish your work in this journal}

Neuropsychiatric Disease and Treatment is an international, peerreviewed journal of clinical therapeutics and pharmacology focusing on concise rapid reporting of clinical or pre-clinical studies on a range of neuropsychiatric and neurological disorders. This journal is indexed on PubMed Central, the 'PsycINFO' database and CAS.

\section{Dovepress}

The manuscript management system is completely online and includes a very quick and fair peer-review system, which is all easy to use. Visit http://www.dovepress.com/testimonials.php to read real quotes from published authors.

Submit your manuscript here: http://www.dovepress.com/neuropsychiatric-disease-and-treatment-journal 